\title{
QUALIFICAÇÃO PROFISSIONAL DE SERVIDORES DE INSTITUIÇÕES PÚBLICAS: A EAD COMO POTENCIALIZADORA PARA FORMAÇÃ̃O E CAPACITAÇÃO DE SERVIDORES NO CONTEXTO DA INOVAÇÃO TECNOLOGICA
}

RECIFE/PE JUNHO/2018

\begin{abstract}
Verônica Danieli de Lima Araújo - FUNDAJ - veronica.araujo@fundaj.gov.br
Sandra Helena Pereira Rodrigues - FUNDAJ - sandra.rodrigues@fundaj.gov.br

José Alexandre Barbosa Pinto - FUNDAJ - alexandre.pinto@fundaj.gov.br
\end{abstract}

Tipo: Investigação Científica (IC)

Natureza: Descrição de Projeto em Andamento

Categoria: Conteúdos e Habilidades

Setor Educacional: EDUCAÇÃO CORPORATIVA

\begin{abstract}
RESUMO
Diante de um contexto cada dia mais direcionado à inovação tecnológica, a Educação a Distància passa a ser uma ferramenta fundamental para que as instituições públicas dinamizem e aprimorem seu capital intelectual. Nesse sentido, faz-se necessário que, haja uma dinâmica que priorize ações voltadas para o mesmo, como a criação de ambientes corporativos e compartilhamento de conhecimento de forma ampla. Este estudo volta-se a analise de um espaço virtual de aprendizagem a distância, com foco na análise das atuais metodologias aplicadas.
\end{abstract}

Palavras-chave: Ead, Capacitação de servidores, Escolas de Governo, SEGU, EV.G 


\section{Introdução}

Partindo-se do principio de que uma melhor qualidade de prestação de serviços, seja em que área for, demanda aprimoramento, habilidades e competência no fazer e o entendimento de todo o contexto envolvido, conhecimento é, e sempre foi uma ferramenta fundamental. Nesse sentido, no âmbito governamental em toda sua trajetória tem se buscado a qualificação dos servidores públicos para melhor desempenho nas funções e serviços prestados a sociedade.A inovação hoje em pauta e, antecedendo a mesma, a revolução tecnológica que vivenciou toda a sociedade nos últimos anos, criaram novas demandas, ampliaram outras formas de fazer, impulsionando assim novas dinâmicas nas atividades, muitas dessas informatizadas.Nesse sentido, a qualificação profissional passou a ter um redesenho e a educação a distância como ferramenta educacional, passou a ser uma ferramenta importante para que mais rapidamente servidores públicos, gestores e toda a administração pública aprimorassem suas habilidades e competências,pois, na medida em que procedimentos e técnicas se modificam, renovam ou mesmo são substituídos por outros ao longo dos anos, torna-se um fato contínuo a necessidade de obtenção de novos conhecimentos ou a sua atualização constante.

Dessa forma,vem se expandido o uso da EAD pelas instituições públicas enquanto instrumento para viabilizar propostas de treinamento, capacitação e educação continuada, uma vez que atividades que demandam o conhecimento e o domínio de procedimentos técnicos e ou administrativos específicos, geram uma amplitude de público a qual só pode ser devidamente atendida através de propostas de capacitação de larga escala.

Nesse sentido, tem-se por objetivo neste artigo buscar elementos que, dêem uma visão prática de como o Governo Federal tem feito uso da EAD enquanto instrumento de qualificação e atualização profissional de servidores públicos. Para tal, buscou-se apoio na pesquisa bibliográfica e documental existente, além da pesquisa de observação, fazendo uso e analise de ambientes hoje utilizados com maior constância e praticidade na área governamental, como o ambiente virtual da ENAP - Escola Nacional de Administração Pública, essa, referencia como Escola de Governo por sua alta qualidade e competência. A escolha da ENAP deu-se pelo fato da mesma, no âmbito da EAD, já estar a bastante tempo investindo recursos para aprimoramento de capacitações através da EAD.

A pesquisa pauta-se nesse conhecimento vivenciado com a Escola Virtual da ENAP ao longo de sua trajetória,até o momento atual, em que se integra ao Portal Único de 
Escolas de Governo, uma vez que já há a algum tempo uma relação com a ENAP, e mais especificamente em analise dos atuais recursos que a mesma vem desenvolvendo. Vale salientar que fez-se uso do ambiente, assim como, voltou-se a analise e acompanhamento de um dos cursos, o que sugestionou a analise desse tema e por tratar-se de ser hoje a EAD uma ferramenta de grande poder instrucional e educativo.

\section{O cenário do uso da EAD no serviço público}

No serviço público, principalmente nos anos atuais, é comum que os funcionários se deparem com um leque de atividades que as vezes demandam a aquisição de novos conhecimentos e habilidades profissionais, pois,

o avanço das Tic's, com enfase na digitalização, implementou nas sociedades mudanças radicais. A era da informação, inaugurada com a disseminação dos veículos de comunicação de massa, cedeu lugar à era do conhecimento. Assim, conhecer já não seria mais privilégio de poucos, mas passaria a ser acessível e, principalmente, produzido por muitos. Fregueses tornaram-se clientes; funcionários precisaram caminhar rumo à capacitação cognitiva e emocional para trabalhar como colaboradores; e administradores buscaram formas de se transformar em gestores(SILVA, 2009,230)

$\mathrm{Na}$ busca de uma atuação cada vez mais ampla e qualitativa, bem como do compartilhamento e circulação de conhecimentos nas instituições, e considerando os diversos campos de atuação do poder público, cada vez mais as propostas de qualificação e treinamento dos servidores são desenvolvidas numa perspectiva de 'Gestão do Conhecimento', a qual pode ser entendida enquanto "uma coleção de processos que governa a criação, a disseminação e a utilização do conhecimento para atingir plenamente os objetivos da organização"(PRETTO, 1996 Apud SILVA,2009, p. 231), e assim, entende-se que "a finalidade da educação no contexto organizacional do setor público deve balizar a geração de novos conhecimentos e um pensamento mais lúcido, visando um horizonte mais amplo de inserção institucional" (MORAES, 2016,p.98)

Numa perspectiva mais abrangente, considerando que há um extenso número de servidores públicos distribuídos em diferentes esferas do poder público (municipal, estadual e federal), visando ofertar uma formação que abrangesse de forma contínua a capacitação dos quadros funcionais, foram criadas ao longo do país várias escolas de governo, que,

são consideradas escolas de governo as instituições destinadas, precipuamente, à 
formação e ao desenvolvimento de servidores públicos, incluídas na estrutura da administração pública federal direta, autárquica e fundacional.

Parágrafo único. As escolas de governo contribuirão para a identificação das necessidades de capacitação dos órgãos e das entidades, que deverão ser consideradas na programação de suas atividades.

(BRASIL, Decreto 5707 de 23 de fevereiro de 2006, Art.4)

A criação e atuação das escolas de governo, principalmente nas instâncias estaduais e municipais pode ser visto como uma forma de atender a necessidade de qualificação e requalificação dos quadros funcionais, prioritariamente em relação a procedimentos administrativos e técnicos, e estas tem importância fundamental no processo de capacitação dos quadros funcionais de diferentes instituições.

No que se refere a ação dessas escolas na modalidade EAD de forma mais efetiva, através do Decreto N. 55707 de 23 de fevereiro de 2006, o Governo Federal instituiu a"Política Nacional de Desenvolvimento de Pessoas" - PNAD - que, entre suas diretrizes "prioriza, no caso de eventos externos de aprendizagem, os cursos ofertados pelas escolas de governo, favorecendo a articulação entre elas, através do Sistema de Escolas de Governo da União -SEGU.

Assim, para atender a públicos diversos de servidores em espaços e tempos também flexíveis, as escolas de governo, através da SEGU passaram a reforçar a oferta de atividades na modalidade a distância,considerando que "a preparação de pessoal qualificado, com maior escolarização, em menor tempo e ao menor custo, não seria possível na modalidade presencial"(MARTINS, 2009,p.235), devido a facilidade de alcance de público, replicação e gestão de atividades, bem como pela otimização do uso de recursos, já que, em sua maioria, os treinamentos/capacitações a distancia são menos onerosos do que os presenciais.

\section{A Escola Virtual de Governo enquanto instância de capacitação servidores: estudo de observação}

Como salientado anteriormente, a ENAP, juntamente com outras escolas de governo, através do SEGU, vem desenvolvendo ao longo de sua trajetória atividades e ações fazendo uso da $E A D$, mas especificamente através de seus ambientes de aprendizagem a distância. Outrora, algumas iniciativas surgiram como alternativas para aprimoramento da proposta de ação em EAD, como a parceria com instituições internacionais, como por 
exemplo em o Acordo de Cooperação Técnica com a Canada School of Public Service (CSPS), assinado em 2013 e do qual participaram 6 Escolas brasileiras regionais de administrarão pública, uma delas a Fundação Joaquim Nabuco sediada em Pernambuco. Salienta-se aqui a importância desse acordo no sentido de transferir conhecimentos e metodologias de EAD, naquele período de grande importância para o crescimento da $E A D$ no âmbito governamental. $O$ que, de fato, deu uma inserção maior da EAD na área governamental, assim não apenas a ENAP mais diversas outras instituições adquiriram conhecimentos relevantes para assim possibilitar e criar novas demandas de projetos em EAD. Ambientes e redes de aprendizagens foram disponibilizados e criados, possibilitando assim, compartilhamento de informações com muitas outras instituições.

Voltando-se ao que hoje o Governo Federal oferece como uma das alternativas de EAD e por conta de sua competência nesse sentido, a ENAP - Escola Nacional de Administração Pública, preside a SEGU, em 2018 toma a iniciativa de criar a Escola Virtual de Governo (EV.G), que consiste num portal único para oferta de capacitação a distância voltado a servidores públicos e cidadãos de todo o país.

A EV.G unifica a oferta de cursos a distancia de diferentes instituições, abordando temáticas ligadas à administração pública e cidadania, "viabilizando o desafio de contribuir para a formação e o desenvolvimento de milhares de servidores públicos e cidadãos"(https://emnumeros.escolavirtual.gov.br)

Ainda de acordo com informações presentes no site https://evg.gov.br , os cursos são ofertados em dois ambientes virtuais distintos:

1. Ambiente virtual MOOC (Massive Open Online Course ou Curso Online Aberto e Massivo) - é utilizado para oferta de cursos de curta e média duração, abertos e gratuitos como alternativa de formação mais aderente ao desenvolvimento rápido de competência para o trabalho;

2. Ambiente virtual SPOC(Small Private Online Course) ou Curso Online Curto e Privado) - é utilizado para a oferta de cursos para grupos menores e personalizados; combina recursos e tecnologia virtual com engajamento pessoal entre professores e alunos. Suporta cursos oferecidos em formato misto, baseados na metodologia de "sala de aula invertida ou "flipped Classroom".

Observou-se assim que, o ambiente virtual MOOC é utilizado para oferta de cursos de grande demanda, em caráter autoinstrucional, ou seja, aqueles onde os alunos no decorrer do curso geralmente não interagem com professores ou tutores, em que os 
conteúdos e atividades são modulados e a avaliação é pautada em exercícios avaliativos sequenciados, disponibilizados no próprio ambiente, os quais, condicionam a obtenção de uma pontuação minima para que o aluno possa prosseguir para os módulos/etapas seguintes dos cursos.

Essa forma de oferta e organização de cursos e atividades, quando refere-se a capacitações cujos conteúdos apresentam um certo grau de complexidade e especificidade, analisou-se que podem fazer com que os alunos, principalmente os que possuem pouca ou nenhuma familiaridade com os conteúdos apresentados,sintam a necessidade de esclarecimentos, orientações; na ausência de contato com professores ou tutores, em alguns momentos os alunos podem se sentir desorientados e até desamparados no seu processo de aquisição de aprendizagens no decorrer dos cursos, o que pode dificultar a aprovação ou servir como elemento de desestímulo, levando ao abandono da formação. Nesse sentido, é necessário levar-se em conta o perfil do alunado e proposta de curso, uma vez que, o servidor público apesar da dedicação ao curso tem, muitas vezes ações prioritarias quando na ativa, o que pode ocasionar, como salientado um desestimulo. Compreende-se que,um curso de carater instrucional, vai requerer do aluno seu total empenho e motivação.

Já os cursos disponibilizados no ambiente virtual SPOC, por serem cursos voltados para grupos menores, possuem conteúdos e atividades que foram criados para atender às especificidades desses grupos; nesse tipo de ambiente, a interação é uma instância necessária para o desenvolvimento das atividades e para uma aquisição mais qualitativa de conhecimentos, portanto as figuras do professor e tutor se fazem presentes nesse tipo de ambiente, tendo contribuição fundamental para o sucesso dos cursos.

De uma forma geral pode-se avaliar que essa iniciativa, até o presente momento, tem se mostrado extremamente exitosa, pois em poucos meses de existência, de acordo com dados disponibilizados no portal, já foram ofertados 132 cursos, com 1.977 turmas formadas, totalizando 1.087 .086 matrículas realizadas, com 584.740 certificados entregues, dados esses que reforçam a importância que a EAD vem adquirindo enquanto modalidade cada vez mais a ser utilizada na capacitação de servidores públicos.

\section{EAD e capacitação de servidores públicos: uma parceria de sucesso?}

A oferta de atividades na modalidade EAD para a capacitação e treinamento, principalmente de servidores públicos tem representado uma ação em sua maior parte com efeitos positivos para os envolvidos no processo. 
Para as instituições, há ganhos qualitativos, pois a princípio se obtém um quadro funcional melhor qualificado e com conhecimentos atualizados, os quais passarão a desenvolver um trabalho mais qualitativo, visto que

funcionários bem treinados, mais do que ficarem satisfeitos com a organização e o investimento feito neles, poderão executar seu trabalho com muito mais facilidade, e, em sintonia com o que há de mais novo no mercado, trazer inovação e eficiência para a realidade de sua corporação(TAMEIRÃO,2017,p.01)

A criação do SEGU e também a recente criação do Portal Único de Escolas de governo, tem permitido uma otimização no uso de recursos materiais e humanos, já que as instituições, com o suporte técnico - operacional ofertado dessa forma, não necessitam dispender continuamente recursos, nem sempre disponíveis, para a capacitação dos seus profissionais, nem alterar significativamente a rotina de trabalho dos funcionários, uma vez que, mesmo que eles se dediquem às atividades no horário de trabalho, na maioria dos casos não é preciso se dispensar a totalidade da carga horária de trabalho, uma vez que não se trata de uma capacitação presencial, mas, apenas o quantitativo de horas que for considerado suficiente de acordo com a complexidade e duração da capacitação/treinamento em questão.

Para os servidores, entre as vantagens que podem ser apontadas na realização de treinamentos/capacitações na modalidade EAD há a questão de que, atividades assíncronas facilitam seu processo de qualificação/atualização profissional, já que eles não precisam se ausentar do seu local de trabalho para fazer a capacitação/curso, sendo possível fazer os cursos em qualquer período de tempo no ano, bem como se dedicar aos mesmos em horários não laborativos; na maioria dos casos, o acesso é facilitado, já que, geralmente os servidores não precisam serem submetidos a processos seletivos ou similares; considerando todos esses elementos, reafirmamos que

ações de e-learning (...)podem ter efeitos positivos para as organizações, como baixos custos, diminuição do tempo que as pessoas demoram para serem treinadas, reduação da necessidade de infraestrutura, aumento do nivel de resposta do negócio(possibilita comunicar ilimitado número de pessas virtual e simultaneamente);mensagens consistentes ou costumizadas, dependendo da necessidade(as pessoas recebem 0 mesmo conteúdo, apresentado da mesma forma;além disso, os programas podem ser customizados de acordo com as necessidades das diferentes audiências); conteúdo pode ser atualizado com fcacilidade e rapidez;aprender 24 horas por dia e sete dias por semana(acesso de qualquer lugar em qualqluer horário); usuários familiarizados com intenet não terão dificuldades parara acessar o curso;universalidade(aproveitamento dos 
protocolos e browsers da Internet, que são universais0; construção de comunidades (a Internet permite construir comunidades para compartilhar conhecimentos e insights após o curso); escala(aumento do número de alunos com um pequeno esforço e custo incremental0 e valorização do servipo ao cliente ( o e-learning pode ajudar o consumitdor a tirar mais proveito do site da organização)(ROSENBERG,2001 apud EBOLI, 2012, p.193)

\section{O que ainda pode ser aprimorado?}

$\mathrm{Na}$ analise proposta quanto ao uso da EAD no serviço publico atraves da analise do portal da ENAP, observa-se uma limitação a ser superada que é o fato de que, justamente por serem cursos que apresentam discussões técnicas ou que necessitam de uma maior atenção e aprofundamento, quando realizados no ambiente de trabalho, mesmo sendo um curso ou atividade realizado na modalidade a distancia, em muitos momentos o funcionário não pode se abstrair de suas atividades de forma a imergir no curso como consideraria satisfatório; em outros casos, pode haver em alguns momentos uma falta de apoio mais efetivo por parte das chefias e colegas de trabalho de modo a permitir que o funcionário priorize as atividades do curso para que obtenha um conhecimento mais proveitoso dos conteúdos que estão sendo abordados.

Outra questão a se considerar é que cursos oferecidos de forma massiva, priorizam temáticas mais amplas, de modo a contemplar um quantitativo maior de alunos para minimizar custos e maximizar resultados; porém, quando o funcionário necessita de uma formação/atualização/capacitação profissional mais específica ou restrita dificilmente ele vai ser contemplado em sua necessidade em cursos ofertados dessa forma, ficando dependente das formações/capacitações presenciais ou então no aguardo de que surja alguma oportunidade de formação via EAD que contemple sua necessidade, o que muitas vezes não acontece, pois a customização de cursos e atividades de acordo com a necessidade de grupos específicos nem sempre acontece e dessa forma ele pode acabar sendo prejudicado em sua necessidade de capacitação/treinamento profissional.

\section{Considerações Finais}

Percebe-se assim que, o uso da EAD no treinamento/capacitação profissional é uma atividade cada vez mais consolidada no cenário das instituições públicas; a criação do SEGU e do Portal Unico tem demonstrado que há a percepção, por parte dos gestores públicos, de que a atualização e aquisição de conhecimentos é uma ação necessária para o êxito institucional e um melhor atendimento ao público; 
Porém, para uma maior efetividade das atividades de formação/capacitação desenvolvidas na modalidade EAD, através das ações da SEGU e dos conteúdos e cursos disponibilizados na EVG, além de todo um planejamento das mesmas, articulação de ações entre as instituições, interesse e colaboração dos servidores a serem capacitados, é necessário um acompanhamento dos alunos durante o seu processo de aprendizagem, e também no período pós treinamento, pois ao colocar em prática o que aprendeu podem surgir conflitos entre teoria e prática que necessitam da mediação de pessoas com maior conhecimento a respeito do que está sendo feito.

Sugere-se assim, uma posterior analise e continuidade da pesquisa, a partir de pesquisa qualitativa e participativa para que, se possa assim medir o impacto desses cursos no serviço público,mais especificamente o portal ora viabilizado pela ENAP, muito embora, acredita-se que, a EAD é uma ferramenta fundamental nesse sentido e que, a ENAP por seu relevante trabalho e estudo no âmbito da EAD, tem com certeza, alguns relatórios que demonstrem esses dados. Nesse sentido, e acreditando ser a EAD, uma ferramenta de grande alcance e cada dia mais amplamente utilizada, a pesquisa nao se encerra, visto que, apenas se inicia, uma vez que, as discussões nesse sentido são amplas requerendo mais analises de outras iniciativas e de novas metodologias que, como se sabe, se ampliam continuamente.

\section{REFERENCIAS}

BRASIL. Decreto n. 5.707, de 23 de fevereiro de 2006. Institui a Política e as Diretrizes para o Desenvolvimento de Pessoal da administração pública federal direta, autárquica e fundacional,e regulamenta dispositivos da Lei no 8.112, de 11 de dezembro de 1990. Lex — Diário Oficial da União. Brasília, 2006.

EBOLI, Marisa Pereira. Sistema de educação corporativa e a EAD. Pp.189-197. IN: LITTO, Fredric Michael; FORMIGA, Marcos. (ORGS.) Educação a distância: o estado da arte.vol.2. 2a ed. São Paulo, 2012. Pearson Education do Brasil.

MARTINS, Herbert Gomes. Educação corporativa: educação e treinamento nas empresas. IN: LITTO, Fredric Michael; FORMIGA, Marcos. (ORGS.) Educação a distância: o estado da arte.Vol.1. São Paulo, 2009. Pearson Education do Brasil.

MORAES, Salus Augusto Resende. A Educação Corporativa como Fator Estratégico para o Comprometimento Organizacional: O Caso da Universidade dos Correios ÚNICO. IN: 
Revista Brasileira de Educação e Cultura - ISSN 2237-3098 Centro de Ensino Superior de São Gotardo Número XIII Jan-jun 2016 Trabalho 06.Pp. 93-114 .

PORTAL UNICO DE ESCOLAS DE GOVERNO. https://evg.gov.br

SILVA, Robson Santos. A educação corporativa - Universidades corporativas. In: LITTO, Fredric Michael; FORMIGA, Marcos. (ORGS.) Educação a distância: o estado da arte.vol.1. 2a ed. São Paulo, 2009. Pearson Education do Brasil.

SISTEMAS DE ESCOLAS DE GOVERNO DA UNIÃO(SEGU). disponível em: https://redeescolas.enap.gov.br/wp_content/uploads/2015/11segu_dezembro_2014 .pdf

TAMEIRÃO, Nathalia. Educação Corporativa: Tudo o que você precisa saber sobre o assunto. 31/07/2017. IN: Blog da Samba. Disponível em:https://sambatech.com/blog/insights/educacao-corporativa/. acesso em: 07/05/2018 